\title{
Using Internet of Things Application for Disposing of Solid Waste
}

\author{
https://doi.org/10.3991/ijim.v14i13.13859 \\ Omar Hashim Yahya $\left({ }^{\bowtie}\right)$ \\ Northern Technical University, Mosul, Iraq \\ Omer_h_yahyaantu.edu.iq \\ Haider Th. Salim ALRikabi \\ Wasit University, Wasit, Iraq \\ Roa'a M. Al_airaji \\ Science College, Babylon University, Iraq \\ Miad Faezipour \\ University of Bridgeport, Connecticut, USA
}

\begin{abstract}
In recent years, the Internet of things has become an urgent need in all of the things that a person needs with the least effort and time. It covers in several areas, including controlling traffic and parking, following up on general and private buildings that what you need of periodic maintenance, and reducing energy through using lighting Smart. In this paper, we focus on important thing and widespread in Iraq, collection of solid waste in the streets without treatment, which causes environmental and psychological damage to the citizen.in addition, the solid waste deposal needs set up sensors(RFID,GPS, ultrasonic, GSM, etc), connecting them to Arduino Uno to accomplish specific intelligent processing that we need. Moreover, the system provides waste containers and warns the concerned departments in the city of the need to empty them when they reach a certain level, which makes the streets healthier, more attractive and free from rodents.
\end{abstract}

Keywords - MSW, IOT, Solid Waste, GSM, Arduino, RFID.

\section{$1 \quad$ Introduction}

A smart city is a comprehensive refurbishment of a city. The modern technology can be used to be under the human service. In addition, the intelligent devices that make highlighting to the importance of modern technology and how it can be applied and learned by humans. The smart city covers several aspects. Firstly, Smart buildings which modern technologies are used to manage and control them in all features (heating, cooling, lighting, security, and cleaning). Secondly, Intelligent transportation, manage the traffic and transportation to provide comfortable and secure seats. Furthermore, 
the passenger will arrive to a place at the required time, and without any crowded. Finally, Smart waste management which considered one of the most important priorities for planning a smart city. It represents the civilizational and environmental frontage of every city. It is one of the most significant problems in Iraq in general, and the city of Mosul particularly because it suffered a collapse in infrastructure. The traditional method used in Mosul city to dispose of solid waste is collecting the Waste in certain containers. It often is full and leaks to the streets, which leads to distorting the city's view with an unpleasant smell. The main reason for choosing the city of Mosul to implement this idea is that it has obtained substantial financial support from the central government in Iraq and neighboring countries and made it a key to the smart city for all other cities in Iraq. In the last decade, consumption patterns of people all over the world have changed. It is due to the various quantities kinds of solid wastes being produced every day, which creates an alarming problem of their disposal. For example, Mosul city has 1.52 million inhabitants and a 3.0 \% growth rate produces about 1033.6 tons per day. The above estimates were obtained through a solid waste survey comprising selected families. The last survey done revealed that the city generated $0.68 \mathrm{~kg} /$ capita/day. Figures (1) and (2) describe urban MSW generation rates in the two sides of Mosul, as a weighted average of the waste data available from various studied quarters [1]. In addition to the large amounts of solid wastes generated by industrial sites, managing the waste collection processes is becoming one of the most convoluted tasks in the rural environment.

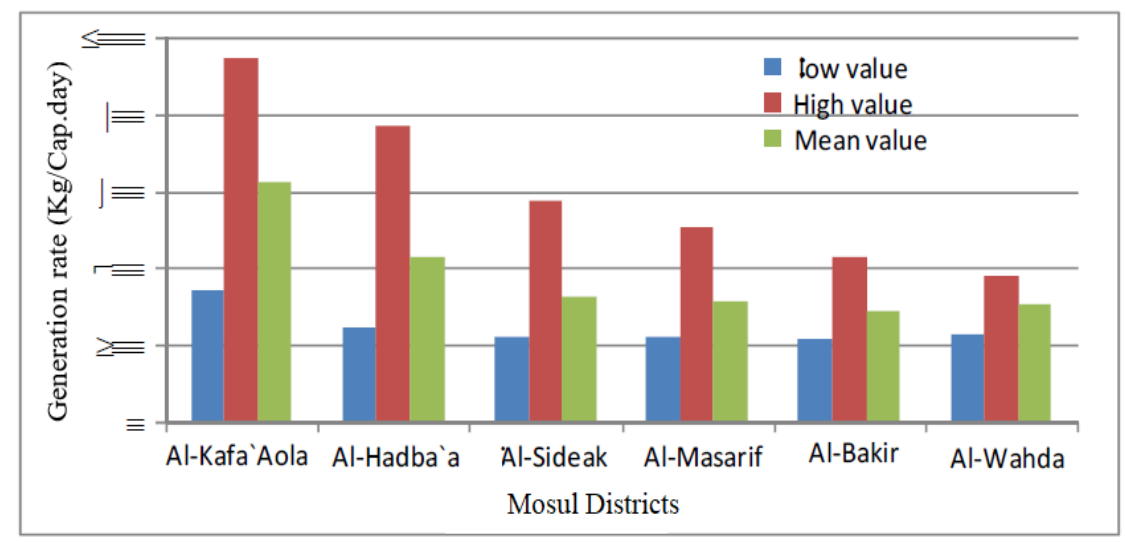

Fig. 1. Urban MSW generation rates in the left side of Mosul 


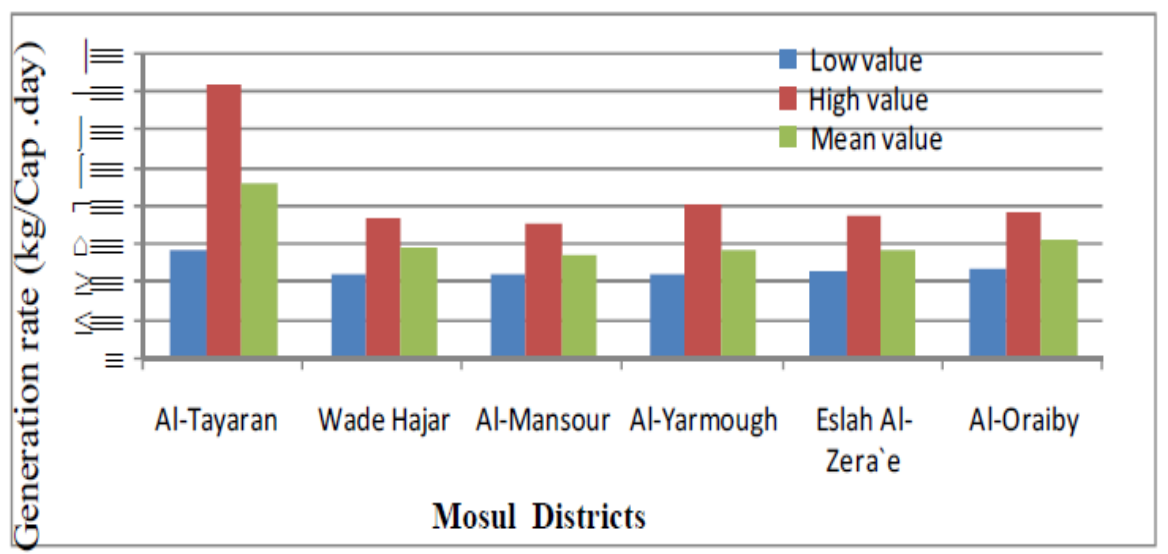

Fig. 2. Urban MSW generation rates in the right side of Mosul

Furthermore, the amount of money spent on solid state management represents about $50-70 \%$ is used for waste collection. Due to the high amount spent on collection, only a low amount is left for the modification of the gathering process [2]. Therefore, an effective way is required for collecting solid waste and utilization of solid waste rather than concentrating on disposal alone. New technologies introduced in the world that offer a new way to optimize waste management systems. These technologies reduce the cost of the collection as well as less time consuming for the collection process in the city. The waste transfer can be controlled by a method more appropriately and effectively by always observing the receptacle status and the trash level. Also, the district can be alarmed when the compartments are full, in this manner advancing unique planning and directing of the trash level [3].

\section{$2 \quad$ Related Work}

This section gives an overview of the techniques which have been proposed for improving the trash collection and monitoring process. A number of studies were carried out on various methods for solid waste monitoring, collecting, as well as management. The system proposed by [4] makes the bin being cleaned once the garbage level exceeds a threshold level. Arduino Uno, GSM module, Ultrasonic sensor are used in this design. The ultrasonic senses the level of garbage in the container. If it crosses the threshold level, it signals the Arduino controller, then the Arduino sends the signal to the GSM module which is used for remote communication with the control center and cleaner. The authors in [5] have provided the smart containers with Raspberry-pi, ultrasonic sensor and flame sensor using an integrated system for monitoring the garbage level in container remotely. The sensors are installed in containers placed in public places. The ultrasonic sensor measures the level of garbage in the container and when it reaches to threshold level it sends the signal to the raspberry-pi. Then a notification message is sent to the control room via the internet. One of the studies designed a system that is 
implemented using a microcontroller, ultrasonic sensor, weight sensor, and RFID module. The ultrasonic sensor checks the level of garbage and sends the signal to the microcontroller. The microcontroller sends the bin number to the Municipality Server which as a result the message goes to the control center and the concerned person [6, 7]. Another method for waste management is introduced in [8] as follows: an 8051 micro-controller is used, in addition to the RF module, IR sensors, RF transmitter and receiver. The container interfaced with a microcontroller-based IR sensor and RF module. The IR sensor checks the level of garbage in the bin and sends signals to the microcontroller, the same signal encoded and sent through the RF transmitter to Central System. Then the signal is received by RF receiver and decoded. Internet service is provided through LAN cable from the modem. Similarly, another paper used $8051 \mathrm{mi}-$ crocontrollers, IR sensor, RF module, Intel Galileo Gen2. In this system, a low-cost embedded system was proposed to make the truck finding the bin through the city or Campus. The bin also has a unique number that facilitates the identification of the garbage when it is full. Details can be reviewed by the authorized person remotely by using the Internet and an immediate response can be given to clean the container [9].In [10], ultrasonic sensors are used to read the level of the bin being filled up. The container is considered three levels of trash being collected in it. Once the garbage reaches a level, the sensor receives the signal of the filled level. This signal is further forwarded to the garbage analyzer as an SMS message using a GSM shield. The drawbacks of this method are the number of ultrasonic sensors installed at three different levels of the bin which increases the cost of the container and also the damage that could happen to the sensors due to the rough action by the users. One of the papers proposed battery-based smart garbage containers $[11,12]$. They can send and receive data between them using wireless mesh networks, and a router and server receive and analyze the data for preparing it to provide services to the users. Furthermore, this method includes a variety of IOT options considering user convenience and improving the battery lifetime through two types of energy-efficient operations of the smart garbage containers: standalone operation and cooperation-based operation. The proposed procedure had been operated as a pilot that is one of the Seoul districts, Republic of Korea, for a year. In [13], a framework has designed in which a camera will be installed at each trash collection point alongside a load cell sensor at the bottom of the trash can. The camera will snap continuous shots of the garbage bin. A threshold level is set which compares the results got from the camera and load sensor. The comparison is done by the microcontroller. After the image being analyzed, information can be obtained about the level of the garbage in the bin, in addition to the weight of the garbage bin extracted from the load cell sensor. Accordingly, the controller processes the information and checks if the threshold level has reached or not. An alternative system described in [14], which helps in showing the nearby container in the neighborhood. people are voluntarily requested to $\log$ into the webpage to locate the containers. The System was proposed a method that helps people to earn points by put recycling materials using their RFID [15]. In addition, the authors implemented new method for attendance student by using RFID[16]. In advance to the old systems, the design got little flexibilities which provide high degree of scalability in terms of collecting the trash, each area is provided with a vehicle and parted into polygons, and the sensor data will go to an onboard computer 
installed in the vehicle. But this is failed due to its cost and efficiency. A few other systems which will alarm the authority center about the full status, so they need to collect the waste in the time scheduled manner but no controlling action is taken if they failed to pick up the waste container in time. It is basically using the Internet of Things (IOT) and the GSM communication as well; informing the various filling levels of the container is becoming more efficient through the ultrasonic sensor and pressure sensor. Using the RFID, identifying the location and authentication can be easier [17, 18].

In [19], a solution is suggested to display a solid waste container status on real time. The system architecture is planned using wireless sensor networks, chosen sensors are used to measure the condition of the containers and ZigBee and GPRS are used as communication techniques. Wireless networking represents the physical layer and ZigBee support large networks, but still have limitation for the smart container usage[20-23]. The System design divided into three levels as lower, middle and upper levels. The lower level is represented by a set of sensors. The selected sensors divided into two parts. The first part is installed underneath the container cover and the other is at the bottom of the bin. The first part consists of ultrasound, an accelerometer, a humidity sensor, and temperature sensors. The latter part consists of the load cell sensor. In the middle level, the readings measured by the sensors are sent to the gateway through ZigBee and GPRS communication shields. The upper level consists of a web server and a database server. The Getaway gets the readings, defines the data, and then saves it in a local database. If the GPRS connection is available, it sends a connection request with the server to the control station through GPRS communication. Finally in paper[24, 25], bins are connected with a microcontroller ARM (LPC2148) based system and provided with IR wireless systems along with a central system showing the level of the trash, on a mobile web browser by Wi-Fi. This paper also has utilized the benefits of a weight sensor and IR sensor to measure the amount of garbage in the bin and to give the information about the bin status. Then, the status is updated on the webpage. The most important part of this paper depends upon the operating of the Wi-Fi module; essential for its implementation.

\section{$3 \quad$ Aims of the Paper}

Compared to the works mentioned above, this work presents a new design and implementation of a smart bin prototype that improves and optimizes the handling of solid urban waste. It will:

1. Improving monitoring and garbage collection system.

2. Reducing the time and effort required to collect the trash.

3. Saving the expenses spent on unneeded items such as bins and vehicles.

4. Reducing the traffic jam and consequently reducing the crowd of the city.

5. Making the environment healthier and decreasing the risk of fire igniting in the trash bins. 


\subsection{Methodology}

In this paper, the intelligent junk observing system is designed to measure waste level in the garbage bin with less time by SMS. It typically sustains the new strong managing of the collection services together for the managers and citizens. The dependable and instant piece of knowledge on the trash bins status might enable efficient timetable management and allow a good route planning for the collection trucks, which are generally arranged randomly. Each bin or container in our proposed system senses the level of the trash via an ultrasonic sensor. Once the bin is full or almost full, it locks the bin so no more trash can be added. Also, it shows a full status light signal to alert people that the bin is full, then notifies the municipality by sending SMS (via a GSM modem) which contains bin ID, bin status, the time the bin is full at, and its location. The bin is still locked until a municipality dustman comes and scans the RFID card to unlock the bin while being emptied. An android app is assumed to receive the message, alert the administrator, and shows well-arranged detailed information about all the full or empty bins distributed in the city along with their location. Figure (3) explains the whole process

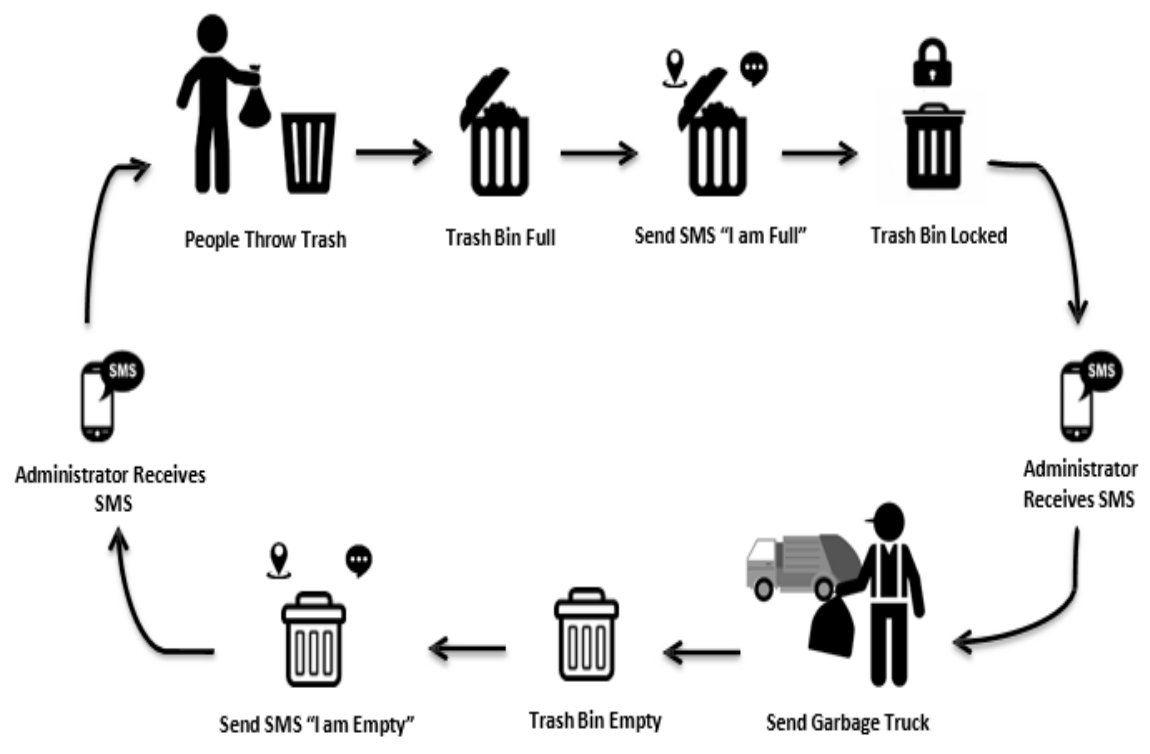

Fig. 3. Paper Methodology.

\section{Components Requirements}

The proposed scheme comprises of an Arduino UNO to control the system operation, an ultrasonic sensor to measure the waste level, a GPS module to get the bin coordinates, an RFID reader to unlock the bin, a GSM shield to send the SMS, 
a door lock to secure the bin cover, a relay to drive the $12 \mathrm{v}$-lock, and two LEDs to show the waste level or the bin status.

\section{System Architecture}

The paper mechanism can be described in brief as following: the proposed system will sense the trash level using the ultrasonic sensor. Two LEDs are used for indicating of garbage level. If the bin is almost filled, it will send a message to administer telling him that the bin with this "ID" is full, please come and collect the waste. At the same time, the bin will be locked automatically. The system will be fixed and the bin will be attached with an RFID module. The only authorized person with an RFID reader can unlock the bin, this adjustment is to avoid the overwhelming of the bin while it is full. on the other hand, the sensed data is sent to the terminal administrator where the data is stored in the database. The GUI is provided through an android application where the administrator gets a detailed idea about all the bins in the city. Figure (4) shows the basic block diagram of the proposed system.

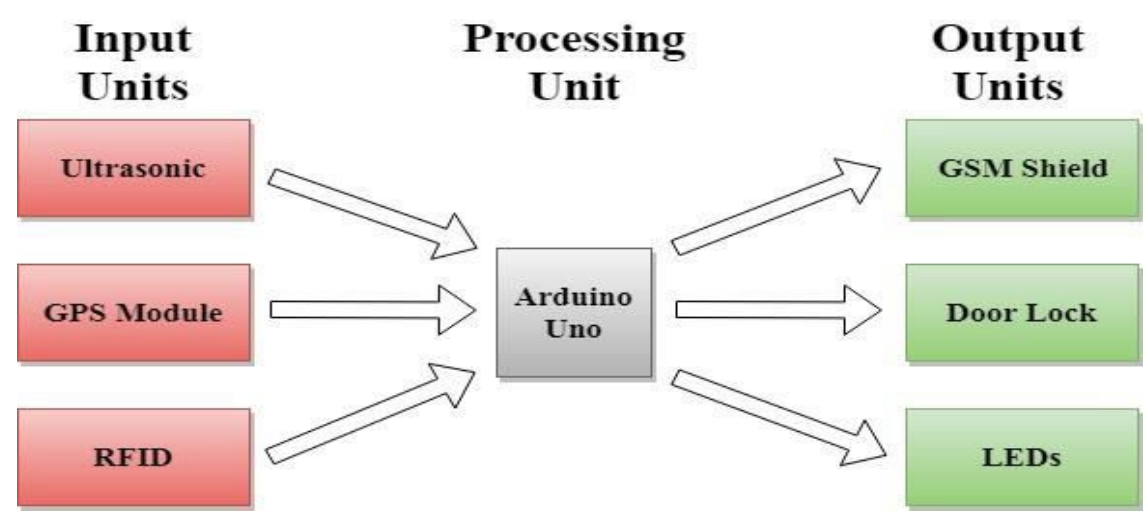

Fig. 4. Basic block diagram of the proposed system

\section{Components Description}

The system components used in this paper design include: an Arduino UNO as a Control unit, ultrasonic sensor, GPS module, and RFID reader as input units, and GSM shield, door lock and LEDs as output units. Figure (5) is the circuit block diagram, Figure (6) shows the Components connection and wiring diagram, Figure (7) is the circuit box, and Figure (9) is a sample of the smart bin of the proposed system. 


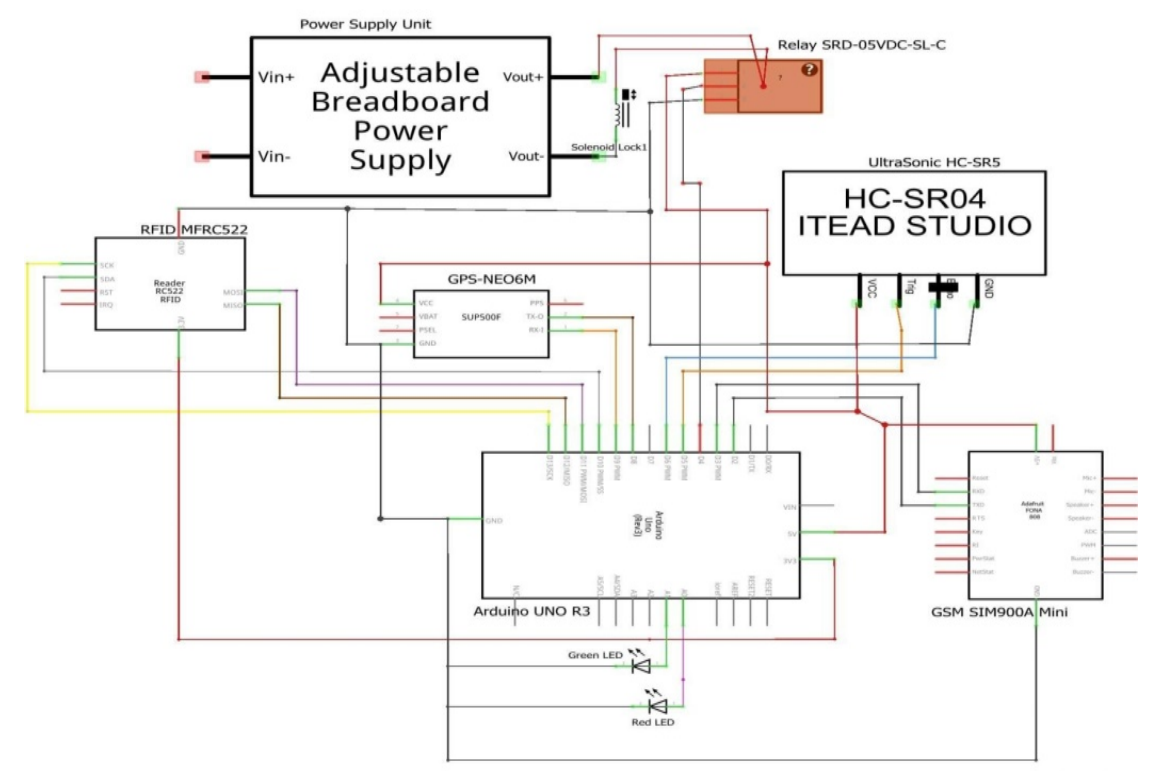

Fig. 5. Circuit diagram of the proposed system

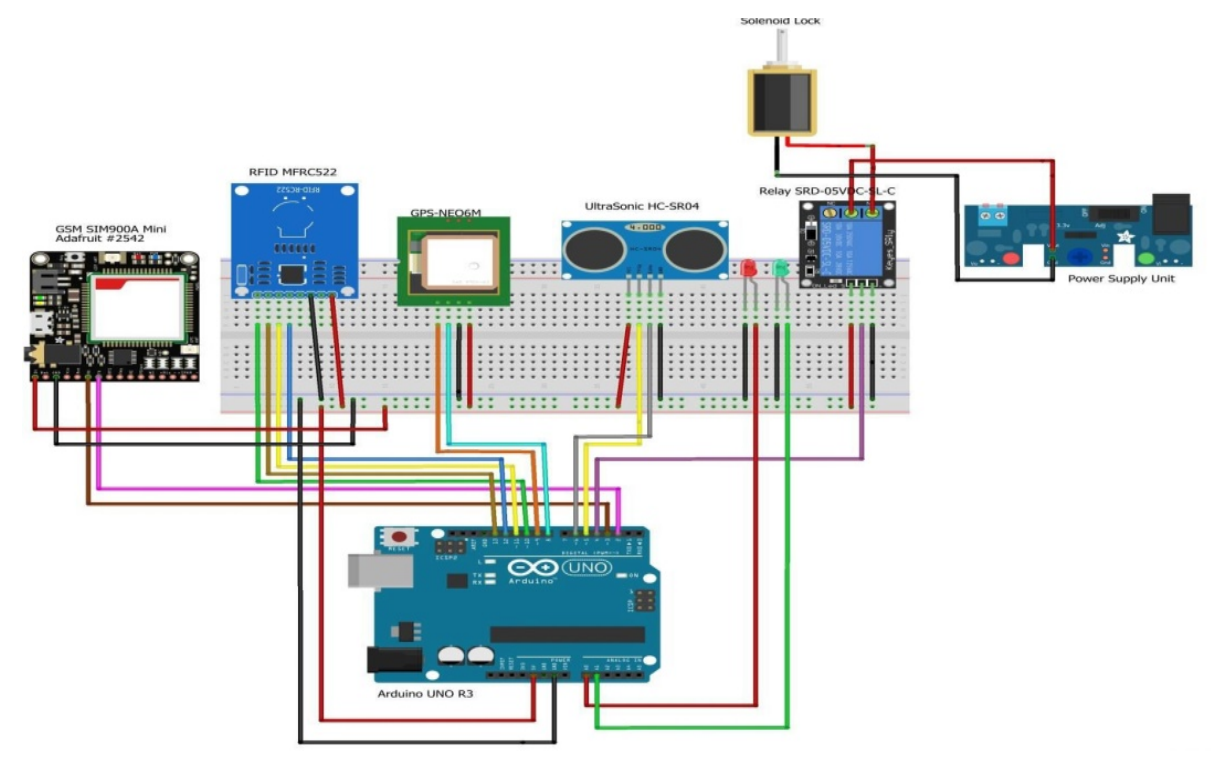

Fig. 6. Components connection and wiring diagram of the proposed system 
Paper-Using Internet of Things Application for Disposing of Solid Waste
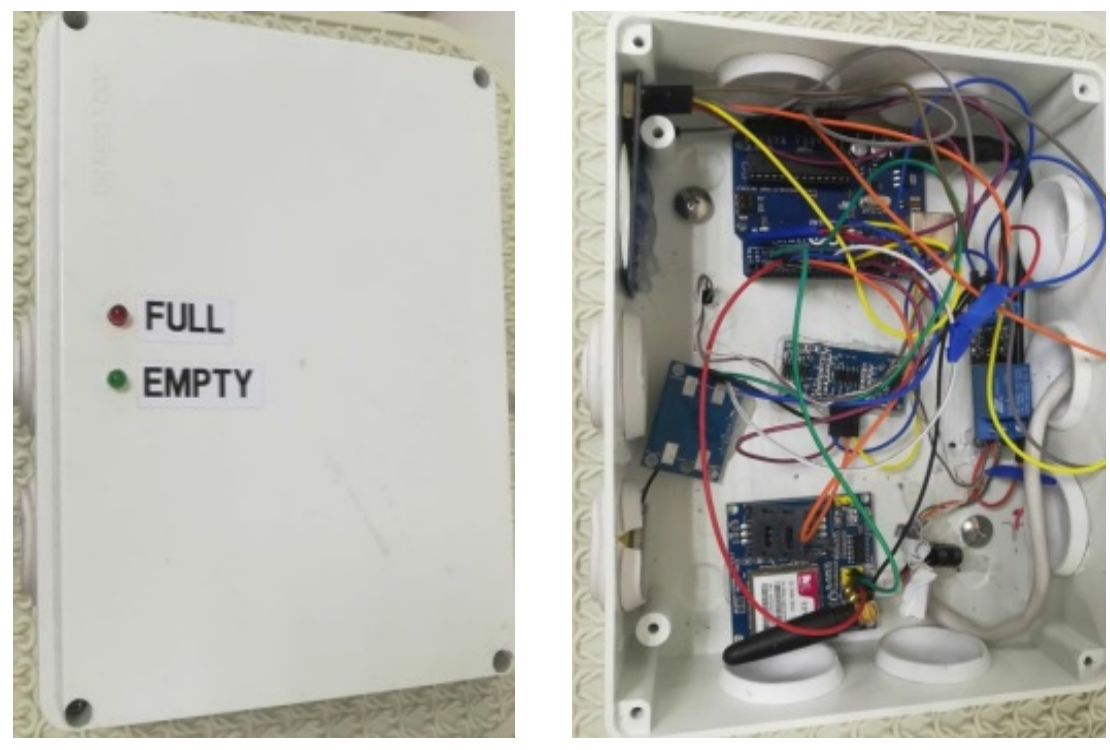

Fig. 7. Circuit box.

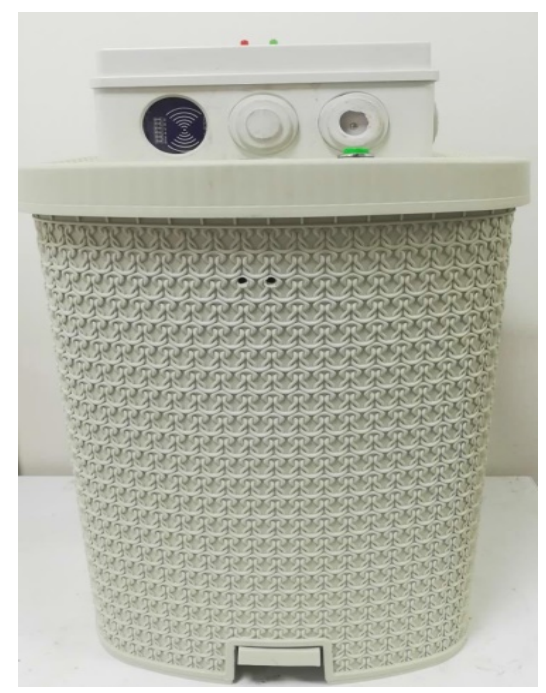

Fig. 8. Sample of the smart bin 


\section{System Software Design}

In the previous section, the hardware components are designed in addition to the architecture design of the system. Now, in this section; the software part of this paper will be introduced and explained. So, to summarize this work, it is split into two parts as we used Arduino IDE to program Arduino UNO controller, and the Android Studio for the android application programming. Figure (9) is the algorithm used to write the Arduino program. As well as Figure (10) shows the Android Studio Interface.

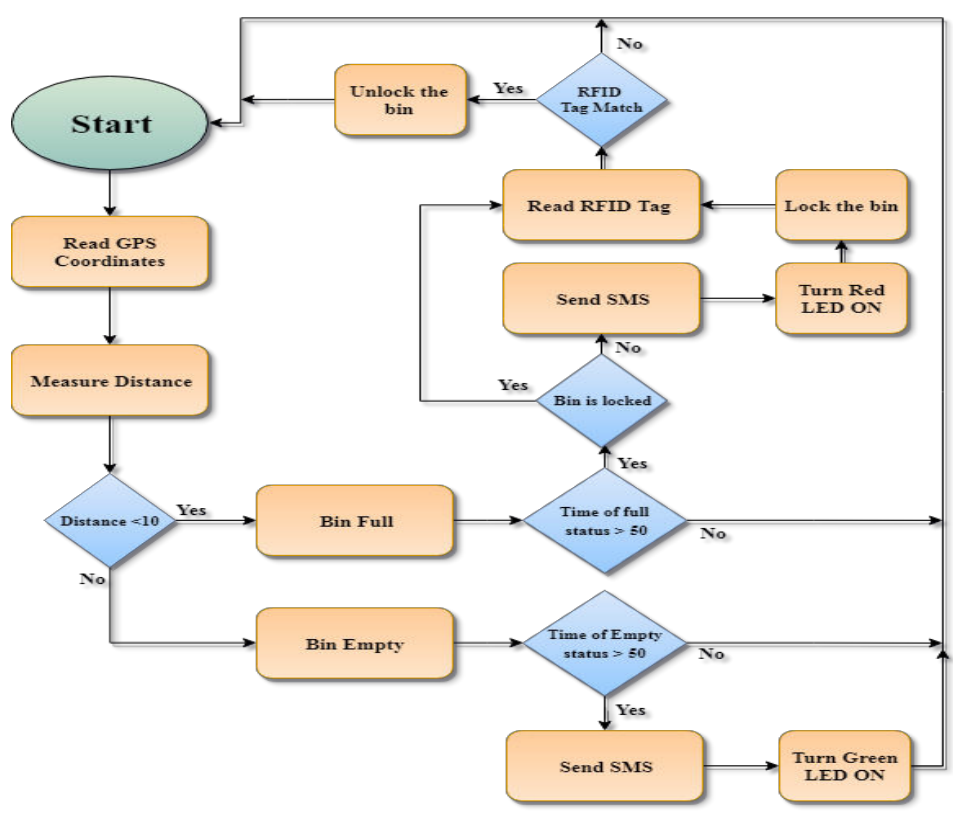

Fig. 9. Software algorithm

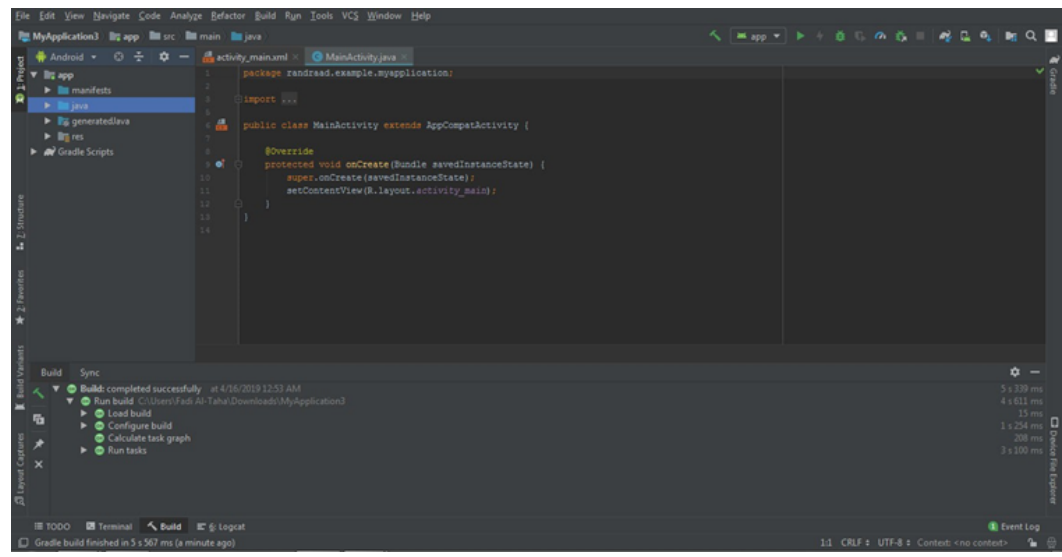

Fig. 10. Android Studio Interface 


\section{$8 \quad$ Experimental Results}

The outputs from the shown tests that all the functionality of the system has accomplished as expected under normal conditions. The proposed system is appropriate to be applied in all domestic regions. The system performance was found satisfactory according to the obtained test results. For the evaluation purpose we summarize the conclusion as follows:

In terms of power consumption, the system uses external power sources of total watts about 16.25. The maximum current consumption per each component as found in our on-hand measurements is (in Amp): Arduino (0.405), Ultrasonic sensor (0.075), GPS module (0.241), RFID module (0.1), GSM shield (10), solenoid Lock (4.8), Relay (0.45), LEDs (0.2). Arduino and lock are powered by $9 \mathrm{v}$ external power source, while all the other components get power from Arduino with 5 and 3.3 volts. Except for the GSM shield which is powered by a separated power provider, since it needs a current of $2 \mathrm{~A}$ with $5 \mathrm{v}$ voltage which is not possible to be provided by Arduino pins. However, a custom-built power bank is recommended with high watts/hour batteries, with the use of the USB DC-DC step-up module, to overcome the issue of the small-scale location, the facility of mov-ability, and the needing for external AC power socket. The application is designed with nine activities and a corresponding number of XML files to build the layout version of the activities. The application requests permission for receiving and reading the SMS messages, accessing the phone location, and using the inter-net connection. Figure (11) represents the application Welcome interface. While Figure (12) shows the menu after running the application. After clicking on one of the buttons in the previous screen, each button will show a list view of the full or empty bins along with the date and time of last update or status change as shown in Figures (13 a, and b). When an item in the list view is clicked, the corresponding information which represents the bin number related to that item along with its location button is displayed (Figure (14)) which enables the responsible to see the actual bin.

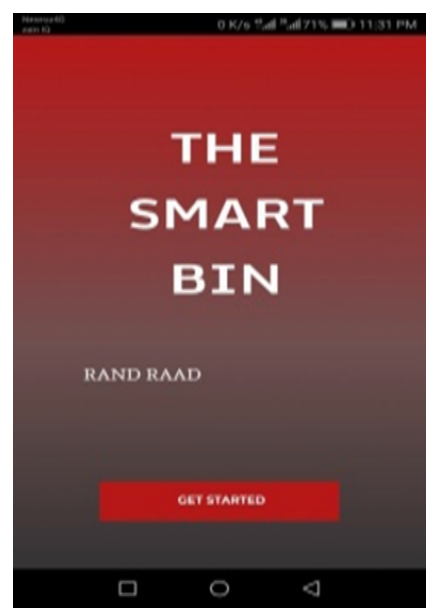

Fig. 11. Interface screen 


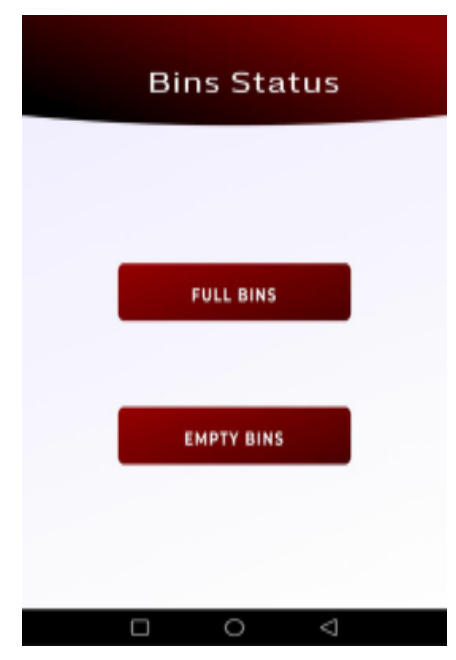

Fig. 12. Bin Status

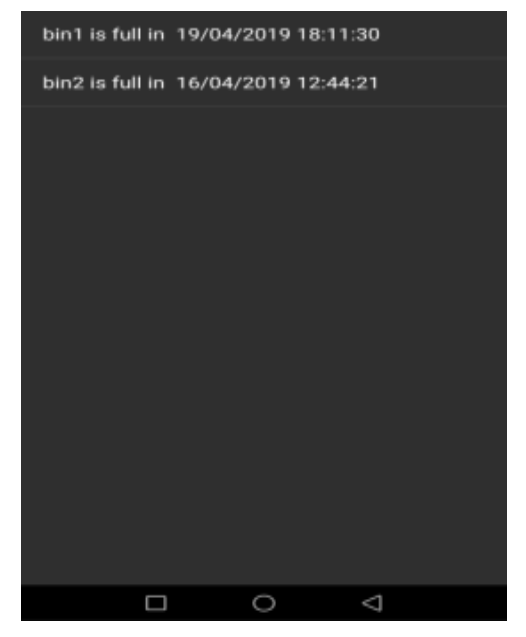

a)

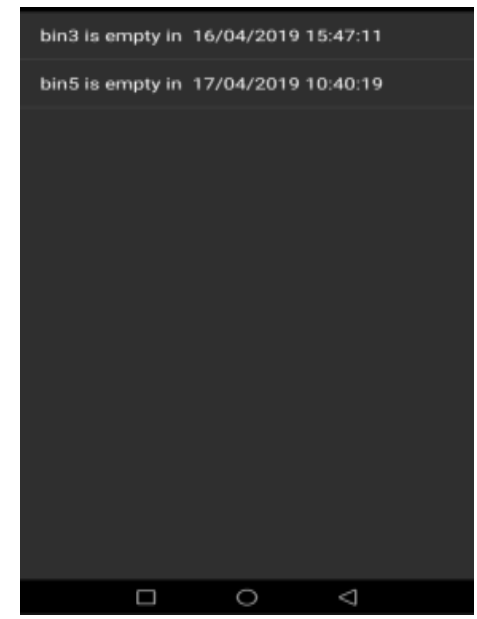

b)

Fig. 13. A. Full Bin, B. Empty Bin 


\section{Bin Details}

Bin Number : bin1

Bin Status : full

Last Update : 19/04/2019 18:11:30

SHOW LOCATION

$\square \quad \circ$

4

Fig. 14.Main Activity.

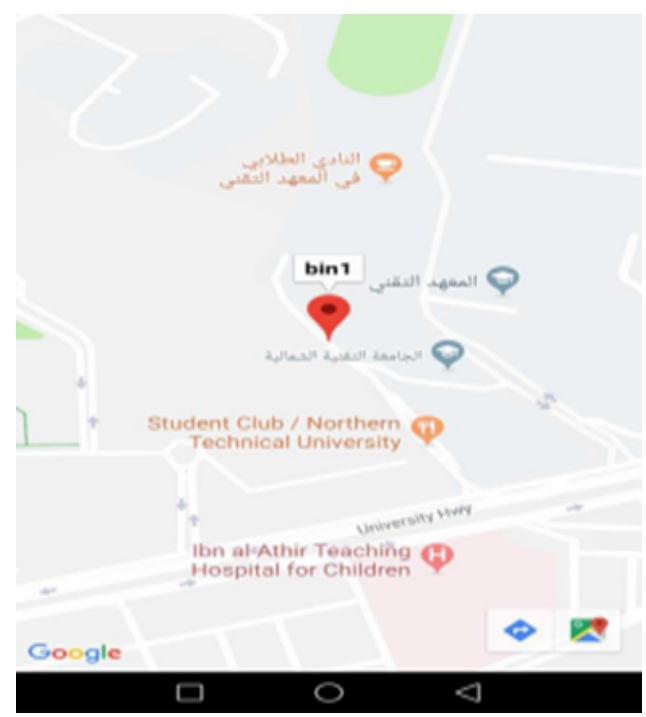

Fig. 15.Bin Location

\section{$9 \quad$ References}

[1] S. M. Al-Rawi and T. A. J. S. J. o. U. o. Z. Al-Tayyar, "A Study on Solid Waste Composition and Characteristics of Mosul City/Iraq," vol. 1, no. 2, pp. 496-507, 2013.

[2] M. El-Fadel, E. Bou-Zeid, W. Chahine, and B. J. W. m. Alayli, "Temporal variation of leachate quality from pre-sorted and baled municipal solid waste with high organic and moisture content," vol. 22, no. 3, pp. 269-282, 2002. https://doi.org/10.1016/s0956-053x (01)00040-X 
[3] M. Hannan, M. A. Al Mamun, A. Hussain, H. Basri, and R. A. J. W. M. Begum, "A review on technologies and their usage in solid waste monitoring and management systems: Issues and challenges," vol. 43, pp. 509-523, 2015. https://doi.org/10.1016/j.wasman.2015.05.033

[4] S. Mahajan, A. Kokane, A. Shewale, M. Shinde, S. J. I. J. o. A. E. R. Ingale, and Science, "Smart Waste Management System using IoT," vol. 4, no. 4, 2017. https://doi.org/10.22 161/ijaers.4.4.12

[5] T. Karvinen, K. Karvinen, and V. Valtokari, make: sensors: a hands-on primer for monitoring the real world with Arduino and raspberry pi. Maker Media, Inc., 2014.

[6] S. V. Kumar, T. S. Kumaran, A. K. Kumar, and M. Mathapati, "Smart garbage monitoring and clearance system using internet of things," in 2017 IEEE International Conference on Smart Technologies and Management for Computing, Communication, Controls, Energy and Materials (ICSTM), 2017, pp. 184-189: IEEE. https://doi.org/10.1109/icstm.2017.808 $\underline{9148}$

[7] I. A. Aljazaery, H. T. S. Alrikabi, and M. R. J. i. Aziz, "Combination of Hiding and Encryption for Data Security," vol. 14, no. 9, p. 35, 2020 https://doi.org/10.3991/ijim.v14i09.14173

[8] N. Sivakumar, A. R. Kunwar, S. K. Patel, S. Kumar, and S. P. Mala, "Design and development of an automatic clustered, assorted trash segregation system," in 2016 IEEE International Conference on Recent Trends in Electronics, Information \& Communication Technology (RTEICT), 2016, pp. 409-413: IEEE. https://doi.org/10.1109/rteict.2016.7807852

[9] S. Shukla and N. J. I. J. o. C. A. Shukla, "Smart Waste Collection System based on IoT (Internet of Things): A Survey," vol. 162, no. 3, 2017. https://doi.org/10.5120/ijca20179 $\underline{13381}$

[10] N. Sharma, N. Singha, T. J. I. J. o. S. Dutta, and E. Research, "Smart bin im-plementation for smart cities," vol. 6, no. 9, pp. 787-791, 2015.

[11] P. Bhandari, L. Lamba, M. Rode, and I. J. V. J. o. E. R. Gorde, "Efficient Garbage Management System," vol. 1, no. 4, 2017.

[12] H. Alrikabi, A. H. Alaidi, and K. J. I. J. o. I. M. T. Nasser, "The Application of Wireless Communication in IOT for Saving Electrical Energy," vol. 14, no. 01, pp. 152-160, 2020. https://doi.org/10.3991/ijim.v14i01.11538

[13] D. Patel, A. Kulkarni, H. Udar, and S. Sharma, "Smart Dustbins for Smart Cities," 2019.

[14] S. L. Beckman, S. Robinson, and S. Pendleton-Knoll, rewarding consumers for recycling packaging: Kimberly-clark seeks shared value. The Berkeley-Haas Case Series. University of California, Berkeley. Haas, 2017. https://doi.org/10.4135/9781526430779

[15] B. S. Costa et al., "Artificial Intelligence in Automated Sorting in Trash Re-cycling," in Anais do XV Encontro Nacional de Inteligência Artificial e Com-putacional, 2018, pp. 198205: SBC. https://doi.org/10.5753/eniac. 2018

[16] H. T. S. ALRikabi, Alaidi, Abdul Hadi M, Abed, Faisal Theyab "Attendance System Design and Implementation Based on Radio Frequency Identification (RFID) And Arduino," Journal of Advanced Research in Dynamical Control Sys-tems, vol. 10, no. 4, p. 6, 2018.

[17] S. Thakker and R. Narayanamoorthi, "Smart and wireless waste manage-ment," in 2015 International Conference on Innovations in Information, Embed-ded and Communication Systems (ICIIECS), 2015, pp. 1-4: IEEE. https://doi.org/10.1109/iciiecs.2015.7193141

[18] N. A. Hussien, I. K. Ajlan, M. F. M. Firdhous, and H. T. S. J. I. J. o. I. M. T. Alrikabi, "Smart Shopping System with RFID Technology Based on Internet of Things," vol. 14, no. 04, pp. 17-29, 2020. https://doi.org/10.3991/ijim.v14i04.13511

[19] A. B. B. Menon, A. K. Nair, J. Vinod, A. Shameela, and T. Adarsh, "Trash Wi-Fi: Wi-Fi password generation and transmission after detection of waste," in 2017 International conference of Electronics, Communication and Aerospace Technology (ICECA), 2017, vol. 2, pp. 72-75: IEEE. https://doi.org/10.1109/iceca.2017.8212764

[20] H. T. Alrikabi, A. H. M. Alaidi, A. S. Abdalrada, and F. T. J. I. J. o. E. T. i. L. Abed, "Analysis the Efficient Energy Prediction for 5G Wireless Communication Technologies," vol. 14, no. 08, pp. 23-37, 2019. https://doi.org/10.3991/ijet.v14i08.10485 
[21] I. A. Ibrahim, H. T. Salim, and H. F. J. W. J. o. E. S. Khazaal, "Investigating the Analysis of Power Saving Mode in IEEE 802.11 for Wi-Fi Communication," vol. 6, no. 3, pp. 13-19, 2018. https://doi.org/10.31185/ejuow.vol6.iss3.100

[22] O. H. Yahya, H. Alrikabi, I. A. J. I. J. o. O. Aljazaery, and B. Engineering, "Reducing the Data Rate in Internet of Things Applications by Using Wireless Sensor Network," vol. 16, no. 03, pp. 107-116, 2020. https://doi.org/10.3991/ijoe.v16i03.13021

[23] A. Alaidi, I. Aljazaery, H. Alrikabi, I. Mahmood, and F. Abed, "Design and Implementation of a Smart Traffic Light Management System Controlled Wirelessly by Arduino," 2020. https://doi.org/10.3991/ijim.v14i07.12823

[24] H. F. Khazaal, H. T. Salem, and A. A. T. J. U. o. T.-Q. J. f. E. S. Abbas, "De-sign and Implementation of Unmanned Autonomous Armed Cart Used for Mili-tary Purposes," vol. 9, no. 1, pp. 103-107, 2018. https://doi.org/10.31663/tqujes.9.1.295(2018)

[25] S. Navghane, M. Killedar, V. J. I. J. o. A. R. i. E. Rohokale, and C. Engineer-ing, "IoT based smart garbage and waste collection bin," vol. 5, no. 5, pp. 1576-1578, 2016.

\section{Authors}

Omar Hashim Yahya, a Lecturer at Northern Technical University, Engineering Technical College of Mosul, Department of Computer Technology Engineering. Northern technical university, Mosul, Iraq, Contact: +9647722118786, Email: Omer h yahya@ntu.edu.iq, The number of articles in national databases - 2, The number of articles in international databases -5 .

Haider Th. Salim ALRikabi, is presently one of the faculty college of engineering, electrical engineering department, Wasit University in Al Kut, Wasit, Iraq. He received his B.Sc. degree in Electrical Engineering in 2006 from the Al Mustansiriya University in Baghdad, Iraq. his M.Sc. degree in Electrical Engineering focusing on Communications Systems from California state university/Fullerton, USA in 2014. His current research interests include Communications systems with mobile generation, Control systems, intelligent technologies, smart cities, and Internet of Things (IoT).

Al Kut city-Hay ALRabee, Wasit, Iraq, Contact: +9647732212637, E-mail: hdhiyab@uowasit.edu.iq, The number of articles in national databases - 10, The number of articles in international databases - 10

Roa'a M. Al_airaji received the Bachelor degree from Department of Computer, College of Science, University of Babylon, in 2012. Received the Master degree from Department of software, College of Information Technology, University of Babylon, in 2018. Currently work as assistant teacher in College of Science, University of Babylon.

Miad Faezipour, current affiliation is Associate Professor: Department of Computer Science \& Engineering, University of Bridgeport, CT 06604, USA, The number of articles in international databases - 144, mailto:mfaezipo@bridgeport.edu

Article submitted 2020-02-19. Resubmitted 2020-03-19. Final acceptance 2020-03-20. Final version published as submitted by the authors. 